\title{
BokSmart: medical management of suspected serious acute spinal cord injuries in rugby players
}

\author{
Robert N Dunn (MB ChB, MMed (Orth), FCS(SA) Orth) \\ Spine Surgery Unit, Division of Orthopaedic Surgery, University of Cape Town
}

\begin{abstract}
Injury to the spinal cord with paralysis during rugby is rare but remains an emotionally charged issue, especially at schoolboy level. The game has evolved over the years with rule changes to reduce injury risk. Scrums were originally perceived as the high-risk phase of play and rule changes in the early 1990s have reduced the number of scrums per game by as much as $40 \%$. Over time the ferocity of play has also increased with bigger, fitter players and possibly more at stake with professionalism. Catastrophic injury rates are low but still occur. Although risk and injury cannot be totally avoided in a contact sport, it does appear that there are deficits in the management of this risk and subsequent injury.

SA Rugby has introduced an educational programme (BokSmart) to increase the level of understanding by players and support staff. This article was prepared for the BokSmart programme in an effort to highlight the deficits and provide a basic understanding of spinal injury.

Terminology, diagnosis and appropriate investigations are dealt with. The early emergency management is discussed as would occur at the first medical point of contact. This allows standardisation of injury assessment so communication between personnel is clear.

An algorithm has been suggested to provide an appropriate management strategy should an injury occur.
\end{abstract}

\section{Introduction}

Injury to the spinal cord during rugby is rare but remains an emotionally charged issue, especially at schoolboy level. Quarrie et al. ${ }^{1}$ report an overall 1.4 spinal cord injuries per annum per 100000 New Zealand rugby players. This has reduced to 0.7 since 2001. This reduction corresponds with the introduction of a local education programme but may also have to do with the change of scrumming laws. ${ }^{2.3}$ Previously many of the injuries were incurred in scrumming,

\section{CORRESPONDENCE:}

Dr Robert Dunn

PO Box 30086

Tokai 7966

Cape Town

Tel: 021 404-5387

E-mail: info@spinesurgery.co.za but with law changes the average number of scrums per game has reduced by $40 \%$. Now many spinal cord injuries occur during open play and particularly during the tackle. Fuller et al. ${ }^{4}$ followed 12 English Premiership clubs for two seasons and found an incidence of 10.9 spinal column injuries per 1000 player match hours. None were catastrophic, but 3 were career ending. He confirmed tackles as the major culprit.

In the South African context, Noakes et al. ${ }^{5}$ reported a total of 8.3 spinal cord injuries per season during 1990 - 1997 in the Western Cape alone. Twenty per cent were schoolboys. The devastating outcome was death in $8 \%$, tetraplegia in $48 \%$ with only $35 \%$ recovering significantly.

Efforts to make the game safer include law changes as well as player, coach and referee education. In addition, early recognition and appropriate management of the spinal cord injury are mandatory.

Injury to the spinal cord not only results in motor and sensory loss, but also autonomic dysfunction, which results in the body's inability to regulate blood pressure, pulse and temperature. Breathing efforts are compromised by loss of voluntary muscle control and these factors threaten the patient's life. The initial management revolves around injury recognition, minimising secondary spinal cord injury, support of essential physiological functions, and avoidance of related complications.

\section{Definitions}

- Cervical - neck.

- Complete spinal cord injury (SCl) - total loss of spinal cord function at a given anatomical level.

- Dermatomes - the area of skin that is supplied by a specific nerve.

- Incomplete SCI - partial loss of spinal cord function at a given anatomical level, with residual sensory or motor function distal to the lesion.

- Neurological - relating to the nerve function.

- Paraesthesia - a sensation of 'pins and needles' in the distribution of the nerves affected. This may be confined to one region of one limb if a single nerve is involved to diffuse involvement of both or all limbs.

- Paraplegia - complete loss of motor (power) function in the lower limbs, i.e. legs, with preservation of normal upper limb function, if the spinal cord is involved.

- Prognosis - future clinical outcome.

- Spinal cord injury (SCI) - damage to the spinal cord which manifests in a loss of motor and/or sensory function.

- Tetraplegia - complete loss of motor (power) function in both upper and lower limbs.

- Thoracic - torso. 


\section{Diagnosis}

The diagnosis is made on the basis of clinical assessment and special investigation.

The initial evaluation is made on the field when a player complains of neck or back pain with associated neurological symptoms. Significant cervical or thoracic pain with focal tenderness of palpation of the spinous processes and a restricted range of cervical motion suggests a significant spinal injury.

Neurological symptoms may be as subtle as paraesthesia (pins and needles) in the limbs to loss of sensation and motor function.

A complete neurological examination by a doctor is required to ascertain whether there is in fact neurological compromise and, if so, to what degree. This requires testing of all dermatomes for sensation and appropriate muscle groups for power. The presence of a sensory level is delineated in the case of a SCl. This manifests at a skin level where there is normal sensation proximal (towards the head), whereas distal (towards the feet) it is altered or absent. The patient is log-rolled and a rectal examination done to confirm the presence or absence of peri-anal sensation, anal tone and voluntary sphincter function. Should this be absent the $\mathrm{SCl}$ is regarded as complete as there is no residual cord function below the lesion. Should any of these be present, the lesion is incomplete, with a better predicted outcome (prognosis). The interpretation will be dealt with in the section on grading of injury.

The patient should be medically stabilised before further investigation, as discussed below.

The first special investigation is X-ray. Commonly the injury is to the cervical area. This can be localised both on the location of the pain and the anatomical lesion from the clinical examination.

A cervical X-ray series consists of an anterior-posterior view of the neck, an open-mouth view and a lateral view. The lateral view should extend from the base of the occiput to T1. Should the distal spine not be visible due to the presence of the shoulders, it should be repeated with manual traction on the arms. Failing this, a swimmer's or flying angel view should be performed.

The X-rays should ideally be assessed by a radiologist but often it is the treating clinician who is faced with the initial interpretation. The lateral view is the most useful but injuries can be missed in up to $30 \%$ of cases. A simple approach is to assess the 5 lines -4 vertical and 1 of convergence (Fig. 1):

- soft-tissue line

- anterior body line

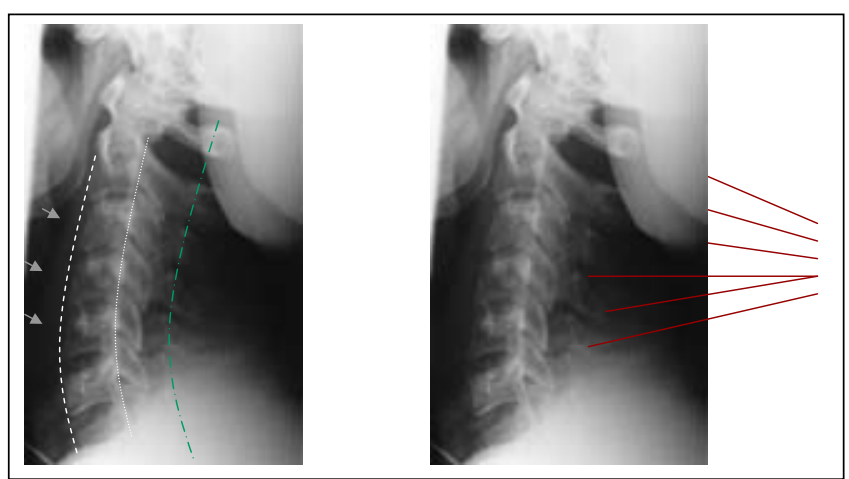

Fig. 1. Normal lateral cervical X-ray depicting the 4 vertical lines of convergence used to assess loss of alignment.

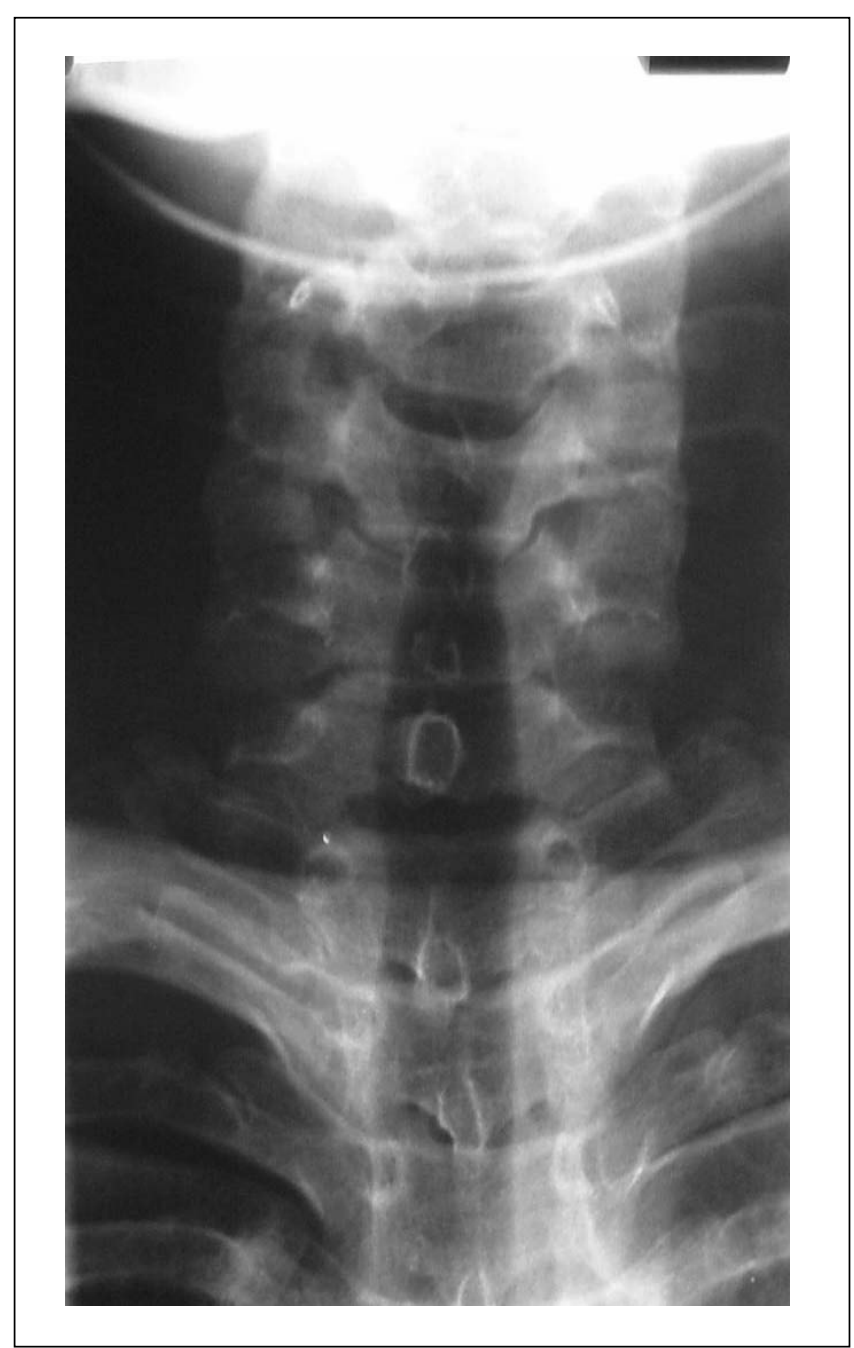

Fig. 2. Normal AP X-ray where the spinous processes can be seen in alignment.

- posterior body line

- spino-laminar line

- convergence of the spinous processes.

When viewing the soft-tissue line, there should be less softtissue shadow than half a vertebral body down to $\mathrm{C} 6$, with up to one body width acceptable below this (grey arrow). There should be a smooth, uninterrupted line running down the anterior aspect of the cervical vertebral bodies from C1 to T1 (white dashed). Likewise for the posterior body line (white dotted) and spino-laminar line (green dashed). A disruption in any of these would suggest loss of spinal column integrity. The lines of convergence are drawn along the axis of the spinous process and should meet posterior to the neck. If they diverge an injury is suspected.

The AP view should be assessed for a rotatory deformity. This is suggested should there be deviation of the spinous process from the midline. The spinous process is shown with the white arrow (Fig. 2).

Should the X-rays be interpreted as normal and there is no neurological deficit, dynamic views would be indicated. This involves flexion or extension views where the patient is asked to maximally flex his neck forward and backwards and X-rays are taken at the extremes. The patient should not be assisted with movement as pain will limit this to within a safe zone. These X-rays are reviewed for 
signs of instability. This includes evidence of listhesis (forward slip) of $3.5 \mathrm{~mm}$ or more, kyphosis of greater than $11^{\circ}$ and loss of the normal contours.

In the case of neurological deficit a MRI scan is required (if available). This is the only way the neurological and other soft-tissue structures can be visualised. It provides the information to make a confident diagnosis and plan safe treatment. Occasionally, if an MRI scan is not readily available one may be forced to manage certain injuries without it. This is a compromise and not the ideal.

\section{Grading of injury}

The injury is graded in terms of two aspects, viz. the integrity of the vertebral column and the neurological status of the spinal cord.

\section{Column integrity}

As regards the column integrity, it is essential to decide if the spine is stable or not. Should there be evidence of instability the spinal cord is at risk, as the spine no longer has the ability of resistance to physiological forces. Instability can be a result from bony or ligamentous injury. Ligamentous injuries are more dangerous as they are not immediately visible on X-ray but suggested by change in alignment. This is more subtle than a fracture.

Cervical injuries are defined according to mechanism. This is a combination of compression or distraction forces in either flexion or extension as per the Allan and Ferguson classification. ${ }^{6,7}$ The commonest injuries seen in the rugby context are the distractive flexion and burst injuries. The way the cervical spine is exposed to force rather than the specific event (tackle, scrum collapse) dictates this. A player can dive into a ruck, and depending how he strikes the ground can exert either a compression force or likewise, by striking his forehead and his body rolling over, create a distractive force on the neck.

A compression flexion injury results in one of the vertebral bodies being fractured, i.e. collapsing. Depending on the degree, this may be limited to deformation of the superior endplate of the body. Should there be more force applied, the inferior anterior part of the body will fracture, creating the 'teardrop' fracture. Despite appearing relatively innocuous on X-ray, this implies that the posterior ligamentous structures have been disrupted and the fracture is unstable. In the extreme case, the teardrop fractures right off, the body retrolistheses (moves backwards) through the spinal canal and transects the spinal cord.

In distraction flexion injury, there is a stretching out of the posterior ligamentous structures, which include the interspinous ligaments and the facet joint capsules. This allows one or both the facet joints to dislocate. With this there is disruption of the anterior disc tissue, creating instability. Should the injury be limited to a unifacet dislocation, the incidence of severe neurological injury is low. A bifacet (both facets) dislocation is evidenced by more than $50 \%$ body width anterior translation on the lateral X-ray, compressing the spinal cord, and resulting in a higher incidence of neurological injury. This type of injury is usually the one that requires urgent intervention as $\mathrm{SCl}$ may be reversible once the compression has been relieved.

\section{Neurological status}

It is important to classify the extent of the injury to be able to succinctly communicate to a referral centre, as it may affect management in the early phase. The American Spinal Injury Association (ASIA) system is utilised.

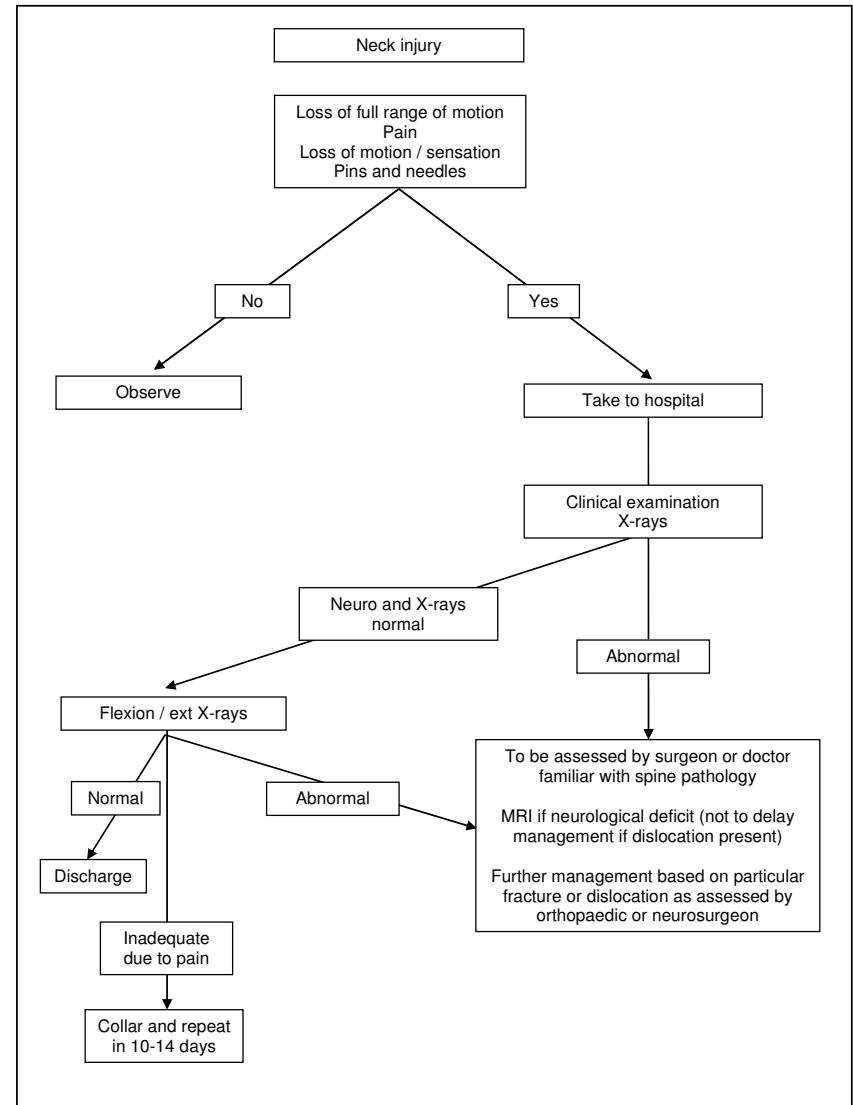

Fig. 3. Flow chart of management of an on-field neck injury.

The assessment is based on determining the level and extent of the injury. The former requires knowledge of anatomy, but for ease, key muscle groups are marked on the ASIA chart (appended). Muscle groups are examined and the level is based on the last normal function level, i.e. full power. Once this is determined, residual distal function is sought. This may be an area just below the lesion, termed a zone of partial preservation, or maintained function throughout the rest of the body. The latter is far more important prognostically ${ }^{8-10}$ because if there is sensation or motor function maintained distally, there is a much better chance of recovery. The lesion is deemed complete if there is no residual distal function and incomplete if function is present. Care must be taken to assess voluntary motor function to command. Sensation must be critically assessed by asking the blinded patient to indicate which leg is being touched as opposed to 'can you feel'. The rectal examination is mandatory in this assessment. All this should be charted on the ASIA score sheet.

The physician should be careful not to interpret anterior chest sensation as preservation of thoracic sensation, as the supraclavicular nerves from the cervical region can supply this area.

Once this assessment has been done, a neurological diagnosis of last functional level, zone of partial preservation (ZPP) and complete/incomplete should be documented.

\section{Preferred list of medical facilities}

It is important that every school or club determines an appropriate hospital in case of suspected spinal cord injury. Facilities vary widely from region to region and access may depend on financial status of the patient.

It is pointless taking a patient with no insurance to a private medical facility if the treating doctor is unable to access the expensive 
imaging modalities. This results in delays while the transfer of the patient to a state facility is arranged.

The degree of spinal injury may dictate the level of care. Should the patient complain of a painful neck but no complaints or evidence of spinal cord involvement, i.e. no paraesthesia or sensory disturbance and full voluntary muscle power, it is likely only X-rays will be required. There is also no extreme urgency in this case, so a stepwise approach can be adopted. This patient can then be taken to a facility where X-rays are available, but not necessarily MRI. This is more applicable in the state environment as most private centres have an MRI, but it may not be available on the weekends. The chosen hospital should be at least a level 2 , with specialist staff available to interpret the $\mathrm{X}$-ray.

Should there be any neurological symptoms, it would be best to attend a hospital with MRI capabilities as well as spinal surgical resources. In the state service this may be limited to level 3 services such as in the Western Cape. It should be ascertained that the private hospital in the school's vicinity has spinal surgical capabilities before utilising their services, in order to avoid delay.

\section{Acute $\mathrm{SCI}$ medical management protocol (Fig. 3)}

Once the injured rugby player arrives in hospital he is assessed by the treating physician. ATLS protocol is followed in terms of emergency management. As $\mathrm{SCl}$ patients can be physiologically unstable, they are best managed in a high-care environment. A dedicated spinal unit is the best. Continuous monitoring of physiological function is necessary with mechanical ventilation available.

The patient should be well immobilised on a firm board to avoid secondary injury. The patient should be supine in a neutral position. Should there be an obvious neck deformity, gentle in-line traction may be necessary for comfort and immobilisation. No forced movement should be performed and movement should be limited if there is associated pain. Preferably a soft thin mattress should be between the board and the patient to prevent pressure sores developing.

Log-rolling, i.e. turning the body in unison, should be performed when examining the patient. This involves three personnel - one with a head grip, one on the shoulders and the other on the pelvis, avoiding any spinal torque when rotating the patient. This allows examination of the back of the neck and torso and facilitates pressure care.

Intravenous access must be obtained and fluids administered to maintain an adequate blood pressure. Patients with $\mathrm{SCl}$ lose their vascular tone, increasing capacitance, and they therefore develop neurogenic shock. They will only transiently respond to fluid resuscitation and this should be limited to avoid pulmonary oedema. Cervical SCl patients may not be able to respond with a tachycardia as there is disconnection of the spine and sympathetic plexus.

A mean blood pressure of more than $70 \mathrm{mmHg}$ is necessary to maintain cord perfusion and minimise the secondary injury. The use of adrenalin may be necessary. Adrenalin 4 amps in $200 \mathrm{ml}$ normal saline diluent can be infused, titrated against the blood pressure. Typically this is infused at $3-10 \mathrm{drops} / \mathrm{min}$ ( 60 dropper). Occasionally with high cervical lesions there is a higher requirement, necessitating a double-strength mixture, i.e. 8 amps adrenalin in $200 \mathrm{ml}$ normal saline at $1-10$ drops per minute. Should there be a persistent bradycardia ( $<40 \mathrm{bpm}$ ), atropine $0.5 \mathrm{mg} \mathrm{IV}$ can be administered.

The use of high-dose steroids is a management choice. There is little evidence of any clinically significant benefit and complication rates remain high. If the physician uses steroids, the NASCIS 3 protocol should be followed, i.e. $30 \mathrm{mg} / \mathrm{kg}$ Depot Medrol over 15 minutes followed by $5.4 \mathrm{mg} / \mathrm{kg}$ per hour for 24 hours if within 4

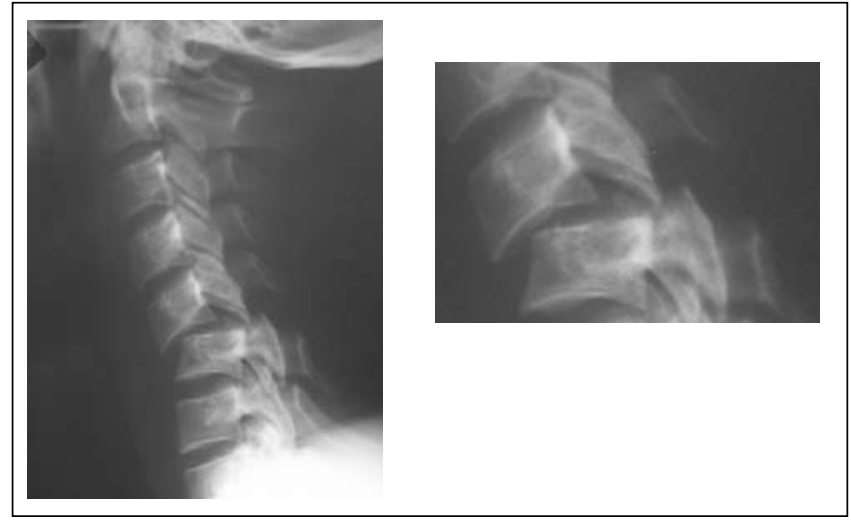

Fig. 4. Case 1. Lateral X-ray confirming a C5/6 unifacet dislocation.

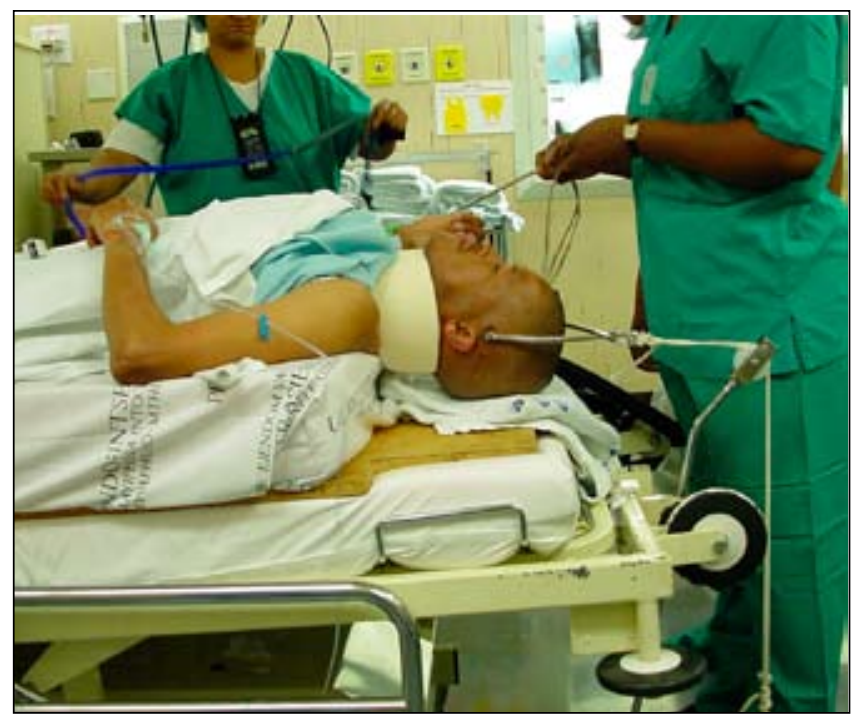

Fig. 5. Note the double mattress to allow extension of the neck after reduction.

hours of injury and 48 hours if within 8 hours. After 8 hours, even the proponents see no benefit. ${ }^{11}$

A urinary catheter should be placed to assess urine output as well as avoid complications from retention related to the $\mathrm{SCl}$.

As these patients frequently develop an ileus, they are placed nil per os and a nasogastric tube is passed.

These patients are at risk of gastritis, and Ulsanic $1 \mathrm{~g} 6$ hourly should be administered per os or via the nasogastric tube.

The patient should be assessed for respiratory difficulty. Frequently patients with a high cervical lesion may fatigue with the increased efforts of diaphragmatic breathing and become hypercapnoeic. Oxygenation is also challenged by atelectasis and possible pulmonary oedema. All patients should receive face-mask oxygen to maintain spinal cord oxygenation and if there is deterioration they should be supported by face-mask CPAP or intubation in extreme cases. It is preferable to intubate early rather than await extensive atelectasis and pneumonia, as this will only prolong the course of ventilation. There is often reluctance to intubate these patients due to perceived poor prognosis, but it should be remembered that in the early phase of spinal shock, there is cord swelling or spinal shock and once this resolves there may be a dramatic improvement. The patient must be given the benefit during this period. ${ }^{12}$

Once the patient is stable physiologically, radiographic investigation is required to assess the injury. This will involve $\mathrm{X}$-rays 


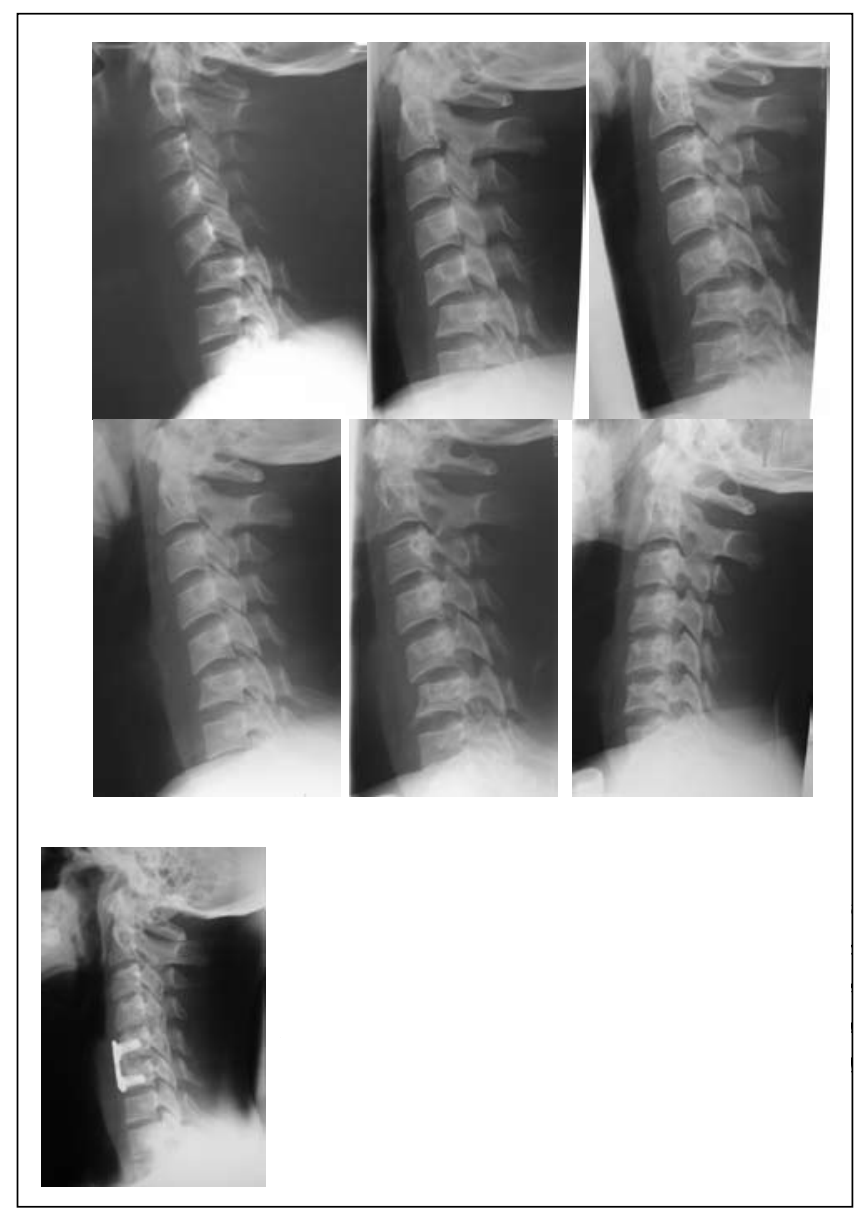

Fig. 6. This series of X-rays demonstrates the dislocated facet distracting, perching and finally reducing into its normal place. Following reduction, an anterior C5/6 fusion was performed with a plate and iliac crest bone graft. This allowed discharge within a few days. An intra-operative open reduction and fusion would also be an acceptable option.

as discussed above as well as an MRI scan if there is neurological injury as well. A CT scan is indicated should there be a suspicious lesion on X-ray that requires further delineation. This is more applicable in the patient with a suspicion of vertebral column injury but no neurological injury.

In the ideal world an MRI is required to assess the SCI. Should this not be available the treating physician needs to decide whether to transfer the patient to another facility or proceed without an MRI. This is a very complex and controversial argument. ${ }^{13}$ If it is clear that the patient is deteriorating neurologically or has a neurological complete lesion and the X-rays confirm a dislocation, it would be reasonable to proceed with closed reduction. There is some weak evidence to suggest early reduction in bifacet dislocations improves outcome, so one would prefer not to delay. ${ }^{14,15}$ In a patient with minimal neurological deficit and a dislocation, there is a risk of deterioration with closed reduction, ${ }^{16}$ and a pre-reduction MRI is preferable to exclude a disc herniation. ${ }^{17,18}$ Although rare, it is a cause for concern.

Should there be a fracture (compression teardrop), there is no reduction required but in-line traction with callipers will assist in realigning the spine.

For both the dislocations and fractures, the head or neck can be immobilised with callipers. For the reduction process, one can

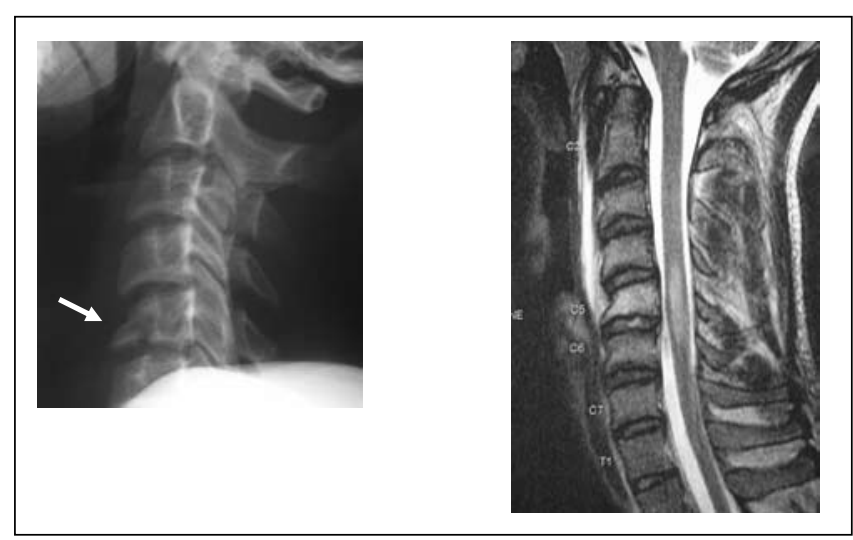

Fig. 7. X-rays show teardrop fragment indicative of a compression flexion injury.The MRI scan indicates increased signal in the fractured body and spinal cord. There is no persistent compression.

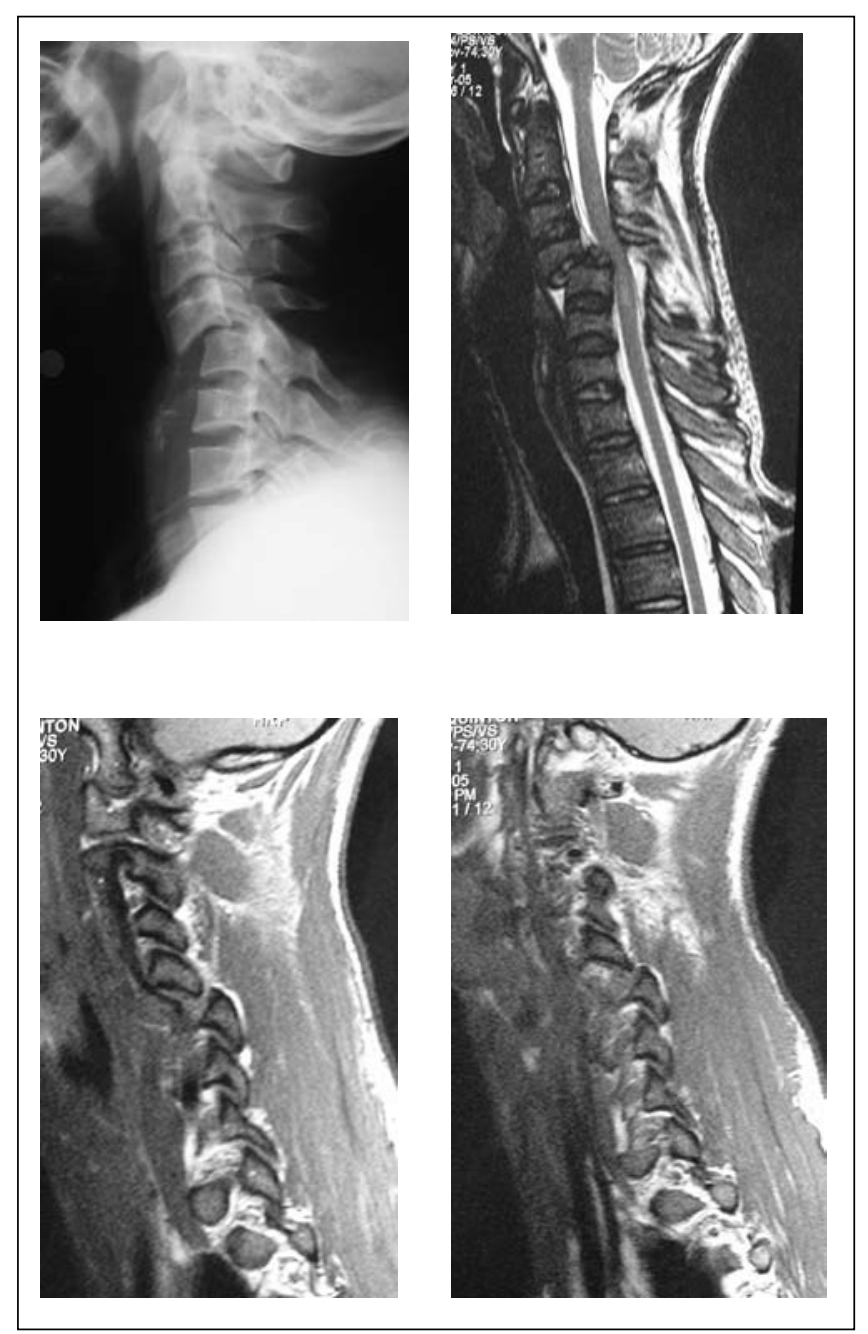

Fig. 8. X-ray confirms a C4/5 anterior listhesis and kyphosis. An urgent MRI scan confirms the bilateral facet dislocation (see para-sagittal views) as well as significant disc behind the C4 vertebral body. This puts the cord at risk during reduction.

start with $5 \mathrm{~kg}$ for the head and $2 \mathrm{~kg}$ per level, positioned in flexion and under X-ray control reduce the facets. The weights can be sequentially increased but seldom beyond $15 \mathrm{~kg}$. Once reduced, the weight can be reduced to $2 \mathrm{~kg}$. A fracture can be maintained with 2 - 4 kg. ${ }^{19,20}$ 
Once reduced, the definitive management is surgical stabilisation if the skill is available. ${ }^{21-25}$ The option of 6 weeks' traction in bed followed by 6 weeks in an orthosis is a poor one. During the period there is risk of complications such as bed sores and pneumonia. ${ }^{26}$ In addition, there may be instability at the end of treatment and surgery may be required in any event.

Should the MRI confirm disc extrusion and thus risk of neurological deterioration with reduction, open (surgical) decompression and reduction can be performed from anterior with relative ease.

The spine should be stabilised surgically either by an anterior plate or posterior fixation.

Chest physiotherapy should be instituted twice a day with assisted coughing. Frequent suctioning should be performed.

Pressure care is mandatory with 3-hourly turns. The use of a pressure reduction mattress (e.g. Huntleigh) is recommended in high cervical injuries.

Deep vein thrombosis prophylaxis is advised with TED stockings and a low molecular weight heparin (LMWH) such as Clexane $40 \mathrm{mg}$ or Fragmin $5000 \mathrm{U}$ daily sc.

\section{Examples}

\section{Case 1 (Figs 4 - 6))}

An 18-year-old male presents with a painful neck following a scrum collapse. His neurological examination is normal.

His lateral X-ray demonstrates a listhesis (forward translation) of the C5 on C6 vertebral body. There is a breach in all the vertical lines and the spines are no longer convergent. On closer inspection, it is clear that one set of facet joints are dislocated. There is obliquity of the $\mathrm{C} 6$ facets compared with $\mathrm{C5}$, suggesting a rotation between the two. The diagnosis is that of a unifacet dislocation. As there is no neurological deficit, closed reduction is an option. Cones callipers were applied, initially in flexion, and serial weights were utilised.

\section{Case 2 (Fig. 7)}

A 19-year-old male presents with diffuse paraesthesia following injury.

There is no need for reduction or decompression. The patient underwent an anterior fusion to re-establish stability. Posterior fusion is an acceptable option.

\section{Case 3 (Fig. 8)}

This 25-year-old man presented with an incomplete cervical SCl. As the patient was incomplete neurologically, urgent surgical intervention is indicated. An emergency anterior discectomy, open reduction and instrumented fusion was performed.

\section{Acknowledgements}

The paper was commissioned by the BokSmart programme, which is a national programme sponsored by ABSA and implemented on behalf of the South African Rugby Union and the Chris Burger/Petro Jackson Player's Fund. The goal of the programme is to teach safe and effective techniques, which will reduce the incidence and severity of injury, make the game safer for all involved and improve rugby performance.

\section{REFERENCES}

1. Quarrie KL, Gianotti SM, Hopkins WG, Hume PA. Effect of nationwide injury prevention programme on serious spinal injuries in New Zealand rugby union: ecological study. BMJ 2007:334;1150-1153.

2. Silver JR. The impact of the 21 st century on rugby injuries. Spinal Cord 2002;40:552-559.

3. Quarrie KL, Cantu RC, Chalmers DJ. Rugby Union injuries to the cervical spine and spinal cord. Sports Med 2002;32(10):633-653.

4. Fuller CW, Brooks JH, Kemp SP. Spinal Injuries in professional Rugby Union: a prospective cohort study. Clin J Sport Med 2007:17(1):10-16.

5. Noakes TD, Jakoet I, Baalbergen E. An apparent reduction in the incidence and severity of spinal cord injuries in schoolboy rugby players in the Western Cape since 1990. S Afr Med J 1999;89(5):540-555.

6. Allan B, Ferguson R, Lehmann T, O'Brien R. Mechanistic classification of closed indirect fractures and dislocations of the lower cervical spine. Spine 1982;7:1-27.

7. Cusick JF, Yoganandan N. Biomechanics of the cervical spine 4: major injuries. Clinical Biomechanics 2002;17:1-20.

8. Lintler DM, Knight RQ, Cullen JP. The neurologic sequalae of cervical spine facet injuries. The role of canal diameter. Spine 1993;8:775-779.

9. Kenneth A, Gerhardt MS. Spinal cord injury outcomes in a population based sample. J Trauma 1991;31(11):1529-1535.

10. Frielingsdorf K, Dunn RN. Cervical injury outcome - a review of 101 cases. S Afr Med J 2007;97:203-207.

11. Bracken MB, Shepard MJ, Holford TR. Methylprednisolone or trilazad mesylate administration after ASCl: 1 year follow up. J Neurosurg 1998;89:699-706.

12. Burns AS, Ditunno JF. Establishing prognosis and maximizing functional outcomes after spinal cord injury: a review of current and future directions in rehabilitation management. Spine 2001;26:S137-145.

13. Jacobs R. MRI pre- and post rapid heavy weight closed reduction. SAOJ 2006;5:40-48.

14. Carlson GD, Minato Y, Okada A, et al. Early time-dependent decompression for spinal cord injury: vascular mechanisms of recovery. J Neurotrauma 1997;14:951-962.

15. Delamarter RB, Sherman J, Carr JB. Pathophysiology of spinal cord injury. Recovery after immediate and delayed decompression. J Bone Joint Surg Am 1995;77:1042-1049.

16. Rizzolo SJ, Piazza MR, Cotler JM. Intervertebral disc injury complicating cervical spine trauma. Spine 1991;16:5187-5189.

17. Robertson PA, Ryan MD. Neurological deterioration after reduction of cervical subluxation. Mechanical compression by disc tissue. J Bone Joint Surg Br 1992;74:224-227.

18. Vaccaro AR, Falatyn SP, Flanders AE et al Magnetic resonance evaluation of the intervertebral disc, spinal ligaments and spinal cord before and after closed traction reduction of cervical spine dislocations. Spine 1999;24:1210-1217.

19. Lee AS, Maclean JC, Newton DA. Rapid traction for reduction of cervical spine dislocations. J Bone Joint Surg Br 1994;76:352-356.

20. Vital JM, Gille O, Senergas J, et al. Reduction technique for uni- and biarticular dislocations of the lower cervical spine. Spine 1998;23:949-954.

21. Keynan O, Dvorak M, Fisher C. Reduction techniques in cervical facet dislocations. Tech Orthopaed 2003;17:336-344.

22. Hadley MN, Fitzpatrick BC, Sonntag VK, et al. Facet fracture-dislocation injuries of the cervical spine. Neurosurgery 1992;30:661-666.

23. Stathoutis B, Govender $\mathrm{S}$. The triple wire technique for bifacet dislocation of the cervical spine injury. Vol. 28, Nr. 2, pp. 123-125, 1997.

24. Doh Koh Y, Lim T, Won You J. A biomechanical comparison of modern anterior and posterior plate fixation for the cervical spine. Spine 2001:26:1521.

25. Key AG, Retief PJ. Spinal cord injuries. An analysis of 300 new cases. Paraplegia 1970;7:243-249.

26. Storm M, Dunn RN. Unifacet cervical fractures. SAOJ 2007; (Spring):1422. 